\title{
¿CRISIS FINANCIERA O CRISIS GLOBAL? LA ECONOMÍA VERDE COMO NECESIDAD Y OPORTUNIDAD ${ }^{1}$
}

\author{
Educadores por la sostenibilidad
}

La gravedad de la crisis financiera mundial, que se está traduciendo en recesión y pérdida de millones de empleos, está llevando a algunos -incluidos influyentes responsables políticos- a pensar que no es el momento de adoptar medidas rigurosas para luchar contra el cambio climático, porque las exigencias económicas que esas medidas comportan podrían agravar la crisis. Lo urgente ahora sería estimular de nuevo el consumo y reactivar el crecimiento económico: el medio ambiente podría y debería esperar.

Sin embargo, estos planteamientos constituyen un nuevo ejemplo de miopía "cortoplacista" que ignora el auténtico origen de la crisis actual y las posibles vías de solución. Porque, como han expresado numerosos expertos, la crisis económica y la crisis ambiental son dos aspectos de una misma problemática y se potencian mutuamente: "La crisis económica que padecemos se deriva de que los ciudadanos de los países desarrollados hemos estado viviendo por encima de nuestras posibilidades, consumiendo bienes que excedían el capital que podíamos reponer", explican Carlos Duarte, Premio Nacional de Investigación, y Carlos Montes, catedrático de ecología en la Universidad Autónoma de Madrid. De hecho, los expertos ya venían prediciendo lo inevitable de graves crisis, si se continuaba apostando por la búsqueda de beneficios a corto plazo sin tomar en consideración los límites del crecimiento en un planeta finito y sus consecuencias de degradación ambiental y social.

Por ello, cualquier demora en la adopción de las necesarias medidas de protección medioambiental y de replanteamiento del sistema productivo, como algunos proponen, solo contribuirá a agravar y multiplicar las crisis. Estudios muy bien fundamentados como, por ejemplo, el que ha dado lugar al conocido "Informe Stern", encargado por el Gobierno Británico en 2006 a un equipo dirigido por el economista Nicholas Stern han estimado el coste, sin duda elevado, de estas medidas; pero al propio tiempo han dejado claro que, si no se actúa con celeridad, el proceso de degradación provocará una grave recesión económica mucho más costosa, con secuelas ambientales irreversibles que pueden dar lugar al colapso de nuestra especie. La pregunta a plantearse no sería, por tanto, cuánto cuesta la adopción de las medidas necesarias sino cuánto está costando ya el no adoptarlas.

No tiene sentido, pues, pensar en salir de la actual crisis económica reincidiendo en los mismos comportamientos de consumo depredador y de crecimiento insostenible que han ido segando la hierba a nuestros pies (degradando todos los ecosistemas terrestres y haciendo crecer las desigualdades y la pobreza extrema) y creando las condiciones de un auténtico colapso. "No podemos resolver los problemas utilizando

${ }^{1}$ Boletín No 32, 15 de enero de 2009. Década por una Educación para la Sostenibilidad. http://www.oei.es/decada/boletin032.htm 
los mismos razonamientos que empleamos para crearlos", advirtió en su día Albert Einstein. Como señala Cristopher Flavin, presidente del Worldwatch Institute, "esta frase debería presidir las aulas de las escuelas de economía, las salas de consejos de administración de las empresas y los grandes hemiciclos donde los legisladores del mundo deciden el curso de las políticas públicas".

Pero la crisis actual tiene otra lectura positiva, superadora del simple "ya lo habíamos advertido" o "esto nos conduce al desastre": podemos y debemos aprovechar la seria advertencia que supone esta crisis para impulsar un desarrollo auténticamente sostenible, una Economía Verde, que Ban Ki-Moon, Secretario General de Naciones Unidas, ha calificado como "La gran máquina de empleos verdes", con inversiones productivas en, por ejemplo, nuevas tecnologías de energía renovable y de eficiencia energética y alimentaria que disminuyan, al propio tiempo, nuestra huella ecológica: "En un momento en que el desempleo está creciendo en muchos países, necesitamos nuevos empleos. En un momento en que la pobreza amenaza con afectar a cientos de millones de personas, especialmente en las partes menos desarrolladas del mundo, necesitamos una promesa de prosperidad; esta posibilidad está al alcance de nuestra mano". Con ese objetivo el Programa de las Naciones Unidas para el Medio Ambiente (PNUMA) ha lanzado un plan para reanimar la economía global al mismo tiempo que, como señala Ban Ki-Moon, "se enfrenta el desafío definitorio de nuestra época: el cambio climático". La crisis es vista así como oportunidad para fomentar una nueva revolución económica e industrial "verde", que desplace la actual insostenible economía "marrón". Es lo que el economista experto en Medio Ambiente, Jeremy Rifkin, ha denominado la Tercera Revolución Industrial que deberá tener a lugar a nivel planetario, asociada al uso de energías renovables, eficientes y descentralizadas con emisiones cero.

Se trata, pues, de una oportunidad, una elección histórica de cambio de modelo a una economía verde frente a la crisis, para poner fin a un rumbo de fracaso y degradación. Una primera andadura en el camino de la necesaria r-evolución para la sostenibilidad que requiere también el replanteamiento de premisas económicas clave y de prácticas empresariales que potencien economías que satisfagan las necesidades básicas de toda la humanidad, al mismo tiempo que protegen el planeta, contribuyendo a construir un mundo sostenible.

No es tiempo, pues, para pausas y demoras en la construcción de un futuro sostenible. Por el contrario, la comprensión de la estrecha ligazón de los problemas a los que la humanidad ha de hacer frente nos obliga a ver en la sostenibilidad la clave para hacer frente a una crisis que no es meramente financiera. Y ello exige una acción social fundamentada, un activismo orientado por el conocimiento, que los educadores hemos de contribuir a desarrollar. Ése ha de ser nuestro decidido compromiso. 